\title{
Pitiose Gastrointestinal Canina: Revisão de Literatura
}

\section{Canine Gastrointestinal Pythiosis: Literature Review}

\author{
Emanoelly Machado Sousa da Silva*a; Kamila Peruchi Fernandes Martinsa; Fabiana Marques Boabaid ${ }^{\text {b; }}$ \\ Luiz Gustavo Schneider de Oliveira ${ }^{\mathrm{c}}$
}

\author{
${ }^{a}$ Universidade de Cuiabá, MT, Brasil.

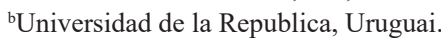 \\ 'Instituto Nacional de Investigação Agropecuária do Uruguai. Uruguai. \\ *E-mail: emanoellymchd@gmail.com.
}

\begin{abstract}
Resumo
A pitiose é uma oomicose provocada pelo agente Pythium insidiosum membro da classe Oomycetes, que produz micélio, semelhantemente aos fungos, porém em contrapartida, sua parede celular não contém quitina, geralmente encontrada nos fungos. Seus hospedeiros mamíferos, aves e o homem, se infectam através de água contaminada com os zoósporos. Em cães, na forma gastrointestinal, os sinais clínicos são variáveis e dependem da porção comprometida, e em função disso, o diagnóstico é baseado na associação de exames clínicos e auxiliares (diagnóstico por imagem, histopatológico, imuno-histoquímica e biologia molecular), e na epidemiologia da doença. O prognóstico dos animais acometidos é reservado, já que frequentemente cursam com o óbito, decorrente de dificuldade em se estabelecer o diagnóstico, e da inespecificidade da atuação dos antifúngicos atuais. Com isso, objetivou-se por meio desta revisão de literatura abordar as características etiológicas e epidemiológicas da doença, com ênfase nos aspectos clinicopatológicos e de diagnóstico, a fim de subsidiar a escolha do tratamento e melhora do prognóstico. Os estudos foram selecionados a partir de livros e buscas na base de dados na biblioteca eletrônica, utilizando como descritores para a busca dos artigos: Pitiose Canina, Gastrointestinal e Pythium insidiosum, selecionando estudos publicados entre 1901 a 2019, publicados em português e inglês que abordassem sobre o tema. Com isso, a pitiose canina é uma doença de extrema importância para Medicina Veterinária e seu conhecimento epidemio-sintomatológico, juntamente com exames complementares são essenciais para o diagnóstico precoce e instituição terapêutica.
\end{abstract}

Palavra-chave: Doença de Cães. Oomiceto. Pythium insidiosum.

\begin{abstract}
Pythiosis is an oomycosis caused by Pythium insidiosum member of the Oomycetes class that produces mycelium, similar to fungi, but in contrast, its cell wall does not contain chitin, usually found in fungi. Its mammalian hosts, birds and humans become infected through water contaminated with zoospores. In dogs, in the gastrointestinal form, clinical signs are variable and depend on the compromised portion, and because of this the diagnosis is based on the association of clinical and auxiliary tests (diagnostic imaging, histopathology, immunohistochemistry and molecular biology), and the disease epidemiology. The prognosis of the affected animals is poor, since they often die, due to the difficulty establishing the diagnosis and the lack of specificity of the current antifungal agents. Thus, the aim of this literature review was to address the etiological and epidemiological characteristics of the disease, with emphasis on clinicopathological and diagnostic aspects, in order to support the choice of treatment and improvement of prognosis. The studies were selected from books and database searches, using as descriptors for the search articles: Canine pythiosis, Gastrointestinal and Pythium insidiosum, selecting studies published from 1901 to 2019, published in Portuguese and English that addressed the subject. Canine pythiosis is an extremely important disease for veterinary medicine and its epidemio-symptomatologic knowledge, along with complementary exams are essential for early diagnosis and therapeutic institution.
\end{abstract}

Keywords: Dog disease. Oomycete. Pythium insidiosum.

\section{Introdução}

Uma oomicose provocada pelo agente Pythium insidiosum, pertencente ao reino Stramenopila, tem sido relatada desde 1987, ocorrendo em espécies de animais domésticos, silvestres e, inclusive, no homem (DE COCK et al., 1987; GAASTRA et al., 2010). Entre os animais, os equinos são os mais afetados com a forma cutânea, sendo raros os casos intestinais. Em segundo, os ovinos na apresentação rinofacial, cutânea e gastrointestinal (DE COCK et al., 1987; FERNANDES et al., 2012; BEZERRA JÚNIOR et al., 2010; MENDONÇA et al., 2017; PESSOA et al., 2012). Já em caninos, as lesões por $P$. insidiosum foram descritas na pele, e em diversos segmentos do trato gastrointestinal (TORRES et al., 2014).
A pitiose é registrada, principalmente, em regiões de clima tropical e subtropical e está associada ao contato de zoósporos móveis com feridas que tenham entrado em contato com áreas alagadas, no entanto, há estudos que demonstram também a presença de $P$. insidiosum no solo e em larvas de mosquitos (DE COCK et al., 1987; GAASTRA et al., 2010; VANITTANAKOM et al., 2014). Ademais, em humanos, a doença já foi relatada, inclusive no Brasil, e sua infecção está associada com as atividades agrícolas e de lazer aquático (MARQUES et al., 2006; SUPABANDHU et al., 2008).

Demodogeral, após ainfecção, a lesãoproduzida emequinos é uma massa com aspecto tumoral, com bordos irregulares, sendo frequentemente ulcerada e serosanguinolenta, 
podendo-se encontrar "kunkers" intralesionais, composto por hifas recobertas por células necróticas, que formam massas branco-amareladas, que variam de 2 a $10 \mathrm{~mm}$ de diâmetro, semelhantes a corais, encontrados exclusivamente em equinos (KRAJAEJUN et al., 2010; DÓRIA et al., 2014). Em cães, ao contrário dos equinos, a forma cutânea, menos frequente, produz lesões ulceradas à nodulares, podendo ser descritas em várias regiões do corpo (DYKSTRA, 1999; GAASTRA et al., 2010).

A forma mais grave e frequente em cães é a gastrointestinal. Geralmente, acomete cães de grande porte, com idade inferior a três anos, com sinais clínicos inespecíficos e dependentes da porção do tubo digestório acometido. Comumente, os cães apresentarem êmese, anorexia crônica, diarreia, por vezes sanguinolenta e, ao exame físico, massas nodulares intraabdominais que podem ser palpáveis (FISCHER et al., 1994). Com a evolução da doença essas lesões podem se expandir e atingir órgãos adjacentes (GROOTERS; FOIL, 2006; JAEGER et al., 2002; MILLER, 1985).

A inespecificidade dos sinais clínicos gerados pela pitiose em cães faz com que sejam necessários métodos de imagem, histopatologia, cultivo e, posterior, zoosporogênese, biologia molecular e imuno-histoquímica para o diagnóstico (GROOTERS, 2003). Essa complexidade faz com que, geralmente, o diagnóstico seja realizado post-mortem, através de necropsia, o que reforça o prognóstico ruim dos animais acometidos, justificado também pelo tratamento antifúngico inespecífico geralmente ineficaz (SANTURIO et al., 2006; ARGENTA et al., 2008).

Com isso, diante do desafio diagnóstico e terapêutico de caninos acometidos pela pitiose gastrointestinal, objetivou-se, através desta revisão de literatura, abordar as características etiológicas e epidemiológicas da doença, com ênfase nos aspectos clinicopatológicos e de diagnóstico, a fim de subsidiar a escolha do tratamento e melhora do prognóstico.

\section{Desenvolvimento}

\subsection{Metodologia}

A presente revisão foi realizada utilizando livros e artigos em periódicos que abordassem a caracterização do agente, a epidemiologia e patogenia da doença, além de seus aspectos clínicos e alterações macroscópicos, métodos diagnósticos e prevenção da oomicose.

Foi realizada uma busca por artigos, nas seguintes bases de dados: Biblioteca Virtual de Saúde (BVS), US National Library of Medicine National Institutes of Health (PubMed) e Scientific Electronic Library Online (SciELO). As palavraschaves utilizadas foram: pitiose canina, gastrointestinal e Pythium insidiosum.

Desse modo, foram selecionados artigos em texto completo, publicados em território nacional e internacional, no período de 1901 a 2019, nos idiomas inglês, espanhol e português, incluindo artigos relacionados com cães infectados por $P$. insidiosum, e como critério de inclusão foi preconizada a relevância e a atualidade do artigo, e de exclusão, os artigos que não se encaixavam nesse contexto, consistindo assim para a amostra final um total de 80 artigos.

\section{2 $\mathrm{O}$ agente}

O agente da pitiose foi isolado pela primeira vez em 1901, em cavalos, por cientistas holandeses, no entanto, por falta de esporulação, o agente não pôde ser identificado, e somente em 1961 recebeu o nome de Hyphomyces destruens (DE HAAN; HOOGKAMER, 1901; DE HAAN, 1902). Ainda assim, posteriormente, observaram o crescimento de zoósporos cultivados em ágar Sabouraud dextrose, transferidos para o meio aquoso e concluíram que Hyphomyces destruens pertencia, na verdade, ao gênero Pythium spp. (AUSTWICK; COPLAND, 1974). No entanto, apenas em 1987, observando a esporulação sexual, foi denominado então Pythium insidiosum (DE COCK et al. 1987).

Por meio de estudos de biologia molecular, observando as diferenças da parede e de composição membranosa do $P$. insidiosum, descobertas pelo sequenciamento de genes da DNA (Ácido desoxirribonucleico) ribossomal, confirmaram que o membro da classe Oomycetes é mais parecido filogeneticamente com algas do que com fungos (SANTÚRIO; FERREIRO 2008). Microscopicamente, o $P$. insidiosum produz micélio, semelhante aos fungos, mas em contrapartida, suas paredes celulares não contêm quitina, principal componente da parede celular fúngica, porém são compostos de celulose e $\beta$ glucanos. Além disso, o oomiceto diferem dos fungos, em função de sua membrana celular não possuir ergosterol, o principal esteroide. Ademais, o processo sexual do oomiceto é baseado em oogamia e desenvolvimento de zoósporos biflagelados em ambientes úmidos (ALEXOPOULOS et al., 1996; GROOTERS, 2003).

O zoósporo, célula única e nucleada, é a porção infectante do Pythium sp., pois com a ajuda de um flagelo posterior, movimenta-se através da água e por quimiotaxia se encistam no tecido lesionado, pela liberação de uma glicoproteína (WALKER; VAN WEST, 2007). Um estudo, realizado por Mendoza et al. (1993), demonstrou que após 15 a 20 minutos encistado o zoósporo produz tubos germinativos tornando-se esférico e dentro de 24 horas a $37^{\circ} \mathrm{C}$, formam vários micélios. No ágar Sabouraud, $P$. insidiosum cresce submerso, formando colônias brancas a incolores, com padrão irradiado irregular.

O ciclo da pitiose foi descrito por Miller em 1983 e compreende, inicialmente, a colonização de plantas aquáticas que servem como substrato para o seu desenvolvimento, dando origem aos zoosporângios. Os zoósporos livres na água encontram outra planta ou um animal e se encistam formando tubos germinativos, dando origem a um micélio, completando seu ciclo.

Durante anos, o Pythium insidiosum foi considerada a única espécie patogênica para mamíferos, no entanto, 
dois estudos recentes, baseados em diagnóstico molecular, demostram a espécie Pythium aphanidermatum infectando o homem, apontando assim outra espécie do gênero com potencial patogênico para mamíferos (CALVANO et al., 2011; DE COCK et al., 1987; FARMER et al., 2015; GAASTRA et al., 2010).

De acordo com a literatura, a identificação e a classificação das espécies de Pythium spp. são baseadas em características morfológicas e fisiológicas, entretanto, são relatadas complicações relacionadas com a contaminação bacteriana, falta de estruturas sexuais e a incapacidade de induzir zoosporogênese na cultura (GROOTERS; GEE 2002; SCHURKO et al., 2003). Desse modo, a identificação de zoósporos biflagelados é considerada altamente sugestiva para diagnóstico do patógeno, mas se faz necessário o uso de ensaios de biologia molecular concomitantes para a identificação definitiva do agente (GROOTERS; GEE, 2002).

\subsection{Epidemiologia e patogenia}

A pitiose é uma doença que ocorre comumente em regiões de clima tropical, subtropical e temperado, reportada em países europeus, Sudeste Asiático e nas Américas. No Brasil, é considerado endêmico no Pantanal Mato-grossense (MENDOZA; AJELLO; McGINNIS, 1996; SANTOS et al., 2014). As condições ambientais influenciam diretamente no desenvolvimento do patógeno, com isso, para haver o crescimento dos zoósporos são indispensáveis temperaturas entre $30^{\circ} \mathrm{C}$ a $40^{\circ} \mathrm{C}$ e, acúmulo de água em banhados e lagos, por isso, geralmente sua ocorrência é verificada durante ou após a estação chuvosa (MILLER; CAMPBELL 1982; SANTURIO et al., 2006).

O primeiro caso de pitiose canina entérica registrado, no Brasil, foi descrito por Riet-Correa et al., (1998) no Estado do Rio Grande do Sul. Os caninos acometidos pela doença, geralmente, são machos de grande porte, como, por exemplo, Labrador Retriever e Pastor Alemão, com idade inferior a três anos e que possuam contato com regiões alagadiças (FISCHER et al., 1994). Porém, há relatos de cães de áreas suburbanas que não entraram em contato com áreas alagadas, apresentando a enfermidade (GROOTERS, 2003). Nesses casos, o mecanismo de desenvolvimento da enfermidade ainda não foi completamente esclarecido.

Os cães acometidos são imunocompetentes e saudáveis (GROOTERS, 2003). Pesquisadores propõem três formas de infecção: duas já consolidadas e relacionadas com a infecção de indivíduos, através da exposição e ou ingestão de água contaminada com os epitélios lesionados ou intactos; e uma terceira via, a partir da observação de $P$. insidiosum em mosquitos do gênero Culex quinquefasciatus na Índia, e em larvas de mosquitos no Estado de Tocantins-Brasil, tendo em vista a possibilidade de transmissão da doença por picada de insetos, especialmente, em regiões tropicais (GAASTRA et al., 2010; SANTURIO et al. 2006; SCHURKO et al., 2003; VILELA et al., 2018).
O desenvolvimento da doença relacionado ao contato de animais com água contaminada pode sofrer influência positiva de dois aspectos: lesões preexistentes no tecido ou a quimiotaxia maior que os zoósporos possuem aos anexos cutâneos. De forma lógica, diante de um quadro de pitiose gastrointestinal, o primeiro aspecto tem sido o único a ser considerado. As lesões anteriores do tubo digestivo de cães têm sido associadas por ingestão, principalmente, de ossos ou de corpos estranhos (TROST et al., 2009; HUNNING et al., 2010; MACÊDO et al., 2014). Em condições favoráveis, como as anteriores descritas, o contato do zoósporo, porção infectante, com o tecido, ocorre com a liberação de uma glicoproteína amorfa pegajosa, que facilita sua adesão denominada protease que é considerada fator patogênico específico dos Oomycetes (MENDOZA; HERNANDEZ; AJELLO; 1993; DAVIS, 2006). Os antígenos liberados pelo $P$. insidiosum modulam a imunidade do hospedeiro, através de uma produção contínua de eosinófilos e mastócitos e bloqueio da resposta imune $\mathrm{T}$ auxiliar 2 (Th2), que ajudam a proteger o patógeno (MENDOZA; MANDY; GLASS, 2003).

Logo após a formação da lesão, a doença progride rapidamente e se não for tratada nos estágios iniciais pode se tornar uma ameaça para a vida do hospedeiro (GAASTRA et al., 2010).

\subsection{Aspectos clínicos e macroscópicos}

A pitiose gastrointestinal canina se caracteriza pelo espessamento que se estende a parede (transmural) do estômago e dos intestinos e massas que podem se expandir e atingir o pâncreas, mesentério, linfonodos, fígado, útero e próstata (MILLER, 1985; JAEGER, ROTSTEIN, LAW, 2002; GROOTERS; FOIL, 2006). Esse aumento de volume, provocado pelo $P$. insidiosum pode induzir obstruções e até intussuscepção (TROST et al., 2009; HUNNING et al., 2010; FIRMINO et al., 2017). Geralmente, o paciente apresenta histórico de insucesso ao tratamento com antibioticoterapia, antiemético e anti-helmíntico (RECH; GRAÇA; BARROS, 2004; FROES et al., 2009)

$\mathrm{O}$ animal pode exibir sinais clínicos variados dependendo do local da lesão, desde inapetência, hipertermia, êmese, quando a doença atinge a parede estomacal e porção inicial do duodeno, anorexia crônica, disfagia, regurgitação, emagrecimento progressivo, tenesmo, diarreia por vezes sanguinolenta e presença de massas nodulares, quando submetido à palpação abdominal (HELMAN; OLIVER, 1999; RODRIGUES et al., 2006; TROST et al., 2009). Apesar de raro, como relatado por Pereira et al., (2010), um mesmo animal pode apresentar as duas formas da doença, como em um caso de um Labrador apresentando pitiose cutânea na região torácica e lesão gastrointestinal (FOIL et al., 1984; TORRES et al., 2014; GALIZA et al., 2014; MENDOZA, 2016). 


\subsection{Diagnóstico}

Em função da constatação de sinais clínicos crônicos associados ao trato digestório, frequentemente, os cães com pitiose gastrotintestinal são encaminhados para exames auxiliares (diagnóstico por imagem, histopatológico, imuno-histoquímica e biologia molecular) (GROOTERS, 2003). Entre esses, técnicas de imagem como radiografias, ultrassonografia e até tomografia podem constatar aumento de volume único ou múltiplo em abdomên ou tórax, não específicos e com uma infinidade de diagnósticos diferenciais (GRAHAM et al., 2000; HUNNING et al., 2010; RECH; GRAÇA; BARROS, 2004; TROST et al., 2009).

Como a pitiose canina pode causar mudanças nos orgãos atingidos, a espessura da parede do trato gastrointestinal não pode ser definida a partir de radiografia simples, mas pode ser avaliada por exame de contraste com sulfato de bário e ultrassonografia (RIEDESEL, 2014).

Em ultrassonografias abdominais de cães com suspeita de oomicose é possível observar espessamento segmentar do trato gastrointestinal, perda da aparência da estratificação normal da parede, diminuição da motilidade e da ecogenicidade da área afetada, além de massas abdominais, linfoadenopatia mesentérica e invasão em orgãos adjacentes, como o pâncreas e vesícula biliar (GRAHAM et al., 2000). Entretanto, esses achados também são frequentemente associados com neoplasias do trato gastrointestinal, como linfossarcoma e, por isso, as avaliações complementares são necessárias. As amostras podem ser obtidas por punção aspirativa, com agulha fina guiada com auxílio da ultrassonografia ou por biópsia (PENNINCK et al., 1993; GRAHAM et al., 2000; FRANK; MAHAFFEY, 2014).

A Tomografia computadorizada (TC) é uma ferramenta importante na Medicina Veterinária, pois fornece possibilidades diagnósticas superiores, quando comparada ao exame Radiográfico convencional, uma vez que na TC as imagens são tridimensionais, e os orgãos são avaliados em secções ou cortes finos, eliminando, assim, a sobreposição e aumentando a sensibilidade diagnóstica (PINTO, 2014).

Todavia, os achados no diagnóstico por imagem não são específicos para o diagnóstico definitivo de pitiose, tornandose necessário o uso concomitante de análises teciduais submetidas ao exame histopatológico para o diagnóstico definitivo da lesão (THRALL, 2014).

Ademais, a citologia é um método diagnóstico utilizado para verificar a predominância celular em um tecido, de modo minimamente invasivo (RASKIN, 2011). Sua aplicação serve para classificar as lesões, auxiliar no diagnóstico, prognóstico e na conduta do caso. Esse procedimento é útil quando utilizado combinado com a avaliação histológica, para uma análise completa do tecido a ser avaliado (ANDREASEN; JERGENS; MEYER, 2012).

A verificação citológica de aspirado por agulha fina de espessamento ou massas, guiado por exame ultrassonográfico, pode fornecer um diagnóstico presuntivo de infecção por Pythium sp. Microscopicamente, é possível observar inflamação piogranulomatosa ou eosinofílica e, ocasionalmente, em conjunto com a inflamação, são notadas estruturas compatíveis com hifas, que somente são visíveis quando há um fundo proteináceo. Porém, adicionalmente, além método de Panótico, colorações de ácido periódico de Shiff - PAS e coloração de nitrato de prata de Grocott (GMS), podem ser utilizadas para evidenciar o oomiceto (GROOTERS, 2003; ANDREASEN; JERGENS; MEYER, 2012).

Outo exame utilizado são as análises sorológicas, técnicas alternativas que auxiliam no diagnóstico precoce da pitiose. O ensaio imunoenzimático (ELISA) indireto foi desenvolvido, pela primeira vez, por Mendoza et al. (1997) e, no Brasil, o ELISA vem sendo utilizado no diagnóstico de equinos, apresentando lesões pelo oomiceto, e foi observada sensibilidade de $97,72 \%$ e especificidade de $90,27 \%$ (SANTURIO et al. 2006).

Em cães e gatos, o ELISA é altamente sensível e específico para detecção de anticorpos anti-Pythium insidiosum, auxiliando no diagnóstico precoce da enfermidade (GROOTERS et al., 2002). Desse modo, o ELISA pode ser uma ferramenta importante no monitoramento depois de terapia cirúrgica, para detecção e recorrência de lesão, além de verificar a duração da terapia médica pós-operatória, observando a diminuição de anticorpos contra o agente (GROOTERS; FOIL, 2006).

O diagnóstico histopatológico é utilizado para conduzir o diagnóstico morfológico da doença. Além disso, também auxilia no diagnóstico etiológico nos casos em que a cultura não possa ser realizada, pois muitas vezes o material é confundido com neoplasias e amostras frescas não são coletadas para avaliação microbiológica (RAKICH; GROOTERS; TANG, 2005; TROST et al., 2009). Em um estudo realizado por Galiza et al. (2014), 83,4\% (192/230), dos casos de micoses e pitioses foram diagnosticadas com base na análise histomorfológica do agente e em suas características histoquímicas, enquanto que em 15,6\% (36/230), o diagnóstico só pode ser confirmado por exames adicionais, demonstrando, assim, a acurácia do exame histopatológico.

A resposta do hospedeiro mediante a doença, na microscopia, pode se apresentar em dois padrões, únicos ou combinados. O primeiro padrão é caracterizado em necrose eosinofílica, debris celulares, colagenólise e um número variável de eosinófilos. O segundo é descrito pela presença de macrófagos epitelioides, células gigantes de Langhans misturadas em diferentes proporções, por vezes, cercadas por cápsula de tecido conjuntivo. Além disso, imagens negativas ou hifas fracamente basofílicas são possíveis de serem visualizadas no interior de lesões necro-eosinofílicas. Contudo, ambas as lesões podem apresentar focos piogranulomatosos (MARTINS et al., 2012; GALIZA et al., 2014). Além disso, a pitiose pode apresentar uma reação de Splendore-Hoeppli 
no histopatológico, caracterizada por material eosinofílico em torno da hifa (HUSSEIN, 2008).

Para melhor caracterização morfológica das hifas, colorações especiais como nitrato de prata de Grocott (GMS) e ácido periódico de Schiff (PAS) podem ser utilizadas. Em contrapartida, mesmo com a evidenciação das hifas por técnicas histoquímicas há a necessidade da diferenciação de fungos entomoformomicetos capazes de provocar lesões semelhantes, tais como: Conidiobolus sp. e espécies de Basidiobolus sp., fazem necessária a utilização de outros métodos de diagnósticos, como a imuno-histoquímica (FUJIMORI et al., 2016; GAASTRA et al., 2010; MARTINS et al., 2012; TROST et al., 2009).

Além disso, a técnica de imuno-histoquímica baseada em anticorpo policlonal vem sendo extensamente utilizada para o diagnóstico da pitiose, pois a partir dessa técnica se confirma o diagnóstico etiológico, tendo como vantagem a capacidade de ser aplicada em tecido parafinizado (GROOTERS, 2003).

Após a suspeita etiológica no histopatológico, para realização do exame é necessário um controle positivo e negativo para a doença e ser realizada a recuperação antigênica com TRIS-EDTA, por exemplo, com o anticorpo primário policlonal anti-Pythium insidiosum na diluição (1:1000). As lâminas são incubadas a $37^{\circ} \mathrm{C}$ durante 60 minutos e, posteriormente, é empregado o anticorpo secundário biotinilado com uma solução estreptavidina conjugada a uma molécula de peroxidase (LSAB + SystemeAP; Dako Corp., Carpinteria, Califórnia, EUA) durante 20 minutos. $A$ revelação pode ser realizada utilizando cromógeno diaminobenzidina (DAB) ou cromógeno Liquid Permanent Red (Dako Cytomation, K0640 [Dako Cytomation, 6392 Via Real, Carpinteria, CA, USA] e, logo após, contra coradas com hematoxilina e eosina. Com isso, o protocolo pode variar dependendo do laboratório, porém as amostras são consideradas positivas quando as estruturas consistentes com a morfologia dos fungos ou hifas são imunomarcadas (TROST et al., 2009; UBIALI et al., 2013). Desse modo, a técnica é utilizada para diferenciar a lesão de espessamento ou produção de massas no trato gastrointestinal por outros fungos como Conidiobolus sp., e Basidiobolus sp. (MACKEY et al., 2015; OKADA et al., 2015).

A técnica de Reação em cadeia da polimerase (PCR) é um diagnóstico no qual há extração do ácido desoxirribonucleico (DNA) do agente através de tecidos embebidos por parafina ou de isolados positivos do oomiceto (AZEVEDO et al., 2012; RODRIGUES et al., 2006; TROST et al., 2009). Existem vários protocolos que podem ser utilizados como o descrito por Möller et al., (1992) e, posteriormente, modificado por Klassen et al., (1996) ou por Grooters e Gee (2002), no qual são utilizados controles positivos e negativos juntamente com a amostra, e depois que o DNA é extraído, a amplificação ocorre com primers variados. As amplificações são visualizadas e fotografadas sob luz ultravioleta e, em seguida, o DNA do agente é sequenciado (RODRIGUES et al., 2006).

Em geral, a análise de sequência de regiões internas do Espaço Ribosomal Intergênico (ITS) e citocromo oxidase II (COX II) tem se apresentado como uma ferramenta importante para o diagnóstico molecular de fungos (RAKEMAN, 2005). No entanto, um estudo filogenético de 31 cepas de Pythium insidiosum, isolados de humanos e fontes ambientais na Tailândia e dois diferentes continentes, demonstrou que árvore filogenética do gene COX II, possui alta eficiência na distinção entre as espécies do oomiceto, quando comparada a ITS (KAMMARNJESADAKUL et al., 2011). E por isso, a análise filogenética desses genes vem sendo amplamente utilizada para o diagnóstico da pitiose em diferentes regiões no Brasil (AZEVEDO et al., 2012).

Um estudo, realizado por Mendoza et al. (1987), foi possível avaliar a relação antigênica de Pythium sp. entre o patógeno em humano e animais, incluindo caninos e espécies não patogênicas do oomiceto, e demonstrou que os isolados de humanos e animais são antigênicamente idênticos e podem produzir anticorpos fluorescentes contra $P$. insidiosum.

\subsection{Tratamento}

O tratamento da pitiose canina é dificultoso em função da composição da parede e pela ausência de ergosterol na membrana do oomiceto, que são os principais alvos da terapia antifúngica (ALEXOPOULOS et al., 1996; FUJIMORI, et al., 2016). Além disso, o sucesso do tratamento dependerá da idade e condição nutricional do animal, do tamanho e tempo de duração da lesão, mas em sua maioria, alguns cães podem evoluir o quadro clínico ao ponto de irem a óbito espontâneo ou serem submetidos à eutanásia (MILLER, 1981; TROST et al., 2009).

Desse modo, os antifúngicos geralmente utilizados são a anfotericina $\mathrm{B}$, cetoconazol, miconazol, fluconazol e itraconazol, além dos compostos iodínicos como iodeto de potássio e de sódio (SANTURIO; LEAL; MONTEIRO, 2003). Em um relato de caso realizado por Fujimori et al. (2016), em um cão com colite por $P$. insidiosum, inicialmente, o paciente foi tratado com iodeto de potássio, porém sem sinais de remissão. Posteriormente, instituiu-se tratamento de itraconazol, associado com terbinafina, durante 160 dias. Exames de diagnóstico por imagem foram realizados, evidenciando redução gradual do espessamento do intestino grosso e, após um ano, o paciente apresentou ganho de peso com remissão dos sinais clínicos. Demonstrando, assim, que o tratamento isolado pode apresentar um sucesso inferior, decorrente da colagenização tecidual provocada pela cronicidade da doença, o que dificulta a atuação medicamentosa (LEAL et al., 2001; HNILICA, 2012).

Além disso, embora a excisão cirúrgica com ampla margem de segurança seja a alternativa indicada, em alguns casos, essa alternativa é inviável em decorrência da 
extensão da lesão, tornando-se necessária a utilização de tratamentos alternativos, como o implementado por Reagan et al. (2019), em três cães, utilizando itraconazol, terbinafina, adicionalmente com corticoide, e os autores observaram resolução completa dos sinais clínicos, regressão das massas e diminuição progressiva dos títulos sorológicos contra o agente.

Estudos com as capofungina, os primeiros capazes de inibir $\beta$-glucanos, um importante composto da parede dos oomicetos, foram realizados em coelhos in vivo e este estudo demonstrou capacidade em reduzir o crescimento da lesão, no entanto, quando interrompido o tratamento, a lesão é retomada. Além disso, o efeito do fármaco é oscilante em função de seu efeito fungistático e por se tornar inapto para o tratamento de animais em decorrência de custo elevado (ALEXOPOULOS et al., 1996; GAASTRA et al., 2010; PEREIRA et al., 2007).

Ademais, devido as dificuldades no tratamento da pitiose, a imunoterapia surgiu como uma técnica alternativa no tratamento em equinos, pois a técnica utiliza vacina a partir de isolados positivos do agente (MILLER, 1981; SANTÚRIO et al., 2003). Estudos demonstram que, após a inoculação do patógeno, ocorrem mudanças na resposta $T$ auxiliar 2 (Th2) que produz interleucina 5 e IL-4, assim como Imunoglobulina $\mathrm{E}$, IgG e IgM, para uma resposta $\mathrm{T}$ auxiliar 1 (Th1), que produz IL-2 e interferon $\gamma$ e está envolvido na expansão de linfócitos T citotóxicos (CTL), indicando um desaparecimento da resposta eosinofílica e expressão da resposta mononuclear (MENDOZA; NEWTON, 2005). Ao analisar fragmentos de tecido infectado após aplicação da imunoterapia no exame histopatológico, indicou uma reação inflamatória mononuclear aparentemente destruindo hifas de P. insidiosum (MENDOZA; MANDY; GLASS, 2003).

No entanto, a imunoterapia utilizando vacina em cães é desafiadora. Um estudo realizado por Mendoza e Newton (2005), envolvendo 18 cavalos e 6 cães, tratados com vacina anti-Pythium, obteve $75 \%$ de sucesso com cavalos e somente $33 \%$ dos cães foram curados, porém as taxas de cura do estudo foram obtidas pela associação de cirurgia e terapia antimicótica.

\subsection{Prevenção}

O conhecimento do ciclo e da epidemiologia da pitiose canina é essencial para a prevenção da doença. A infecção por Pythium insidiosum ocorre após a exposição dos susceptíveis com lesões preexistentes, desse modo se deve evitar a exposição de cães em áreas alagadas contaminadas com o oomiceto ou que tenha relato da doença em outros animais, como equinos (GAASTRA et al., 2010).

\section{Conclusão}

A pitiose canina se torna uma doença de extrema importância para Medicina Veterinária, em decorrência de ampla distribuição nos meio ambientes alagados, bem como pelo fato dos animais se contaminarem através de quimiotaxia da pele intacta ou tecido lesionado, sendo essa última a forma associada às lesões do tubo digestivo. As alterações da forma gastrointestinal incluem a formação de massas ou espessamento segmentar desse sistema. Em consequência disso, suas manifestações clínicas são altamente variáveis, o que consequentemente dificulta o diagnóstico clínico, tornando-se necessária a utilização de uma associação de exames para identificação específica do agente etiológico e para a seleção de uma terapia apropriada. Entretanto, a terapia é desafiadora, pois os tratamentos convencionais utilizados não são específicos para a constituição de parede do oomiceto, e os fármacos específicos possuem eficácia variada e de custo elevado para ser instituído na clínica. Com isso, o conhecimento epidemio-sintomatológico, juntamente com exames complementares são essenciais para o diagnóstico precoce e instituição terapêutica associada para a melhora do prognóstico do animal.

\section{Referências}

ALEXOPOUlOS, C.J.; MIMS, C.W.; BLACKWELL, M. Introductory mycology. New York: John Wiley \& Sons, 1996.

ANDREASEN, C.B.; JERGENS, A.E.; MEYER D.J. Cavidade oral, trato gastrointestinal e estruturas associadas. IN: RASKIN, R.E.; MEYER, D.J. Citologia clínica de cães e gatos: Atlas colorido e guia de interpretação. Rio de Janeiro: Elsevier, 2012.

ARGENTA, J.S. et al. In vitro activities of voriconazole, itraconazole, terbinafine, alone or in combination against Pythium insidiosum isolates from Brazil. Antimicrob Agents Chemother., v.52, n.2, p.767-769, 2008. doi: 10.1128 / AAC.01075-07.

AUSTWICK, P.K.C., COPLAND, J.W. Swamp cancer. Nature, v.250, p.84, 1974.

AZEVEDO, M.I. et al. Pythium insidiosum: Morphological and molecular identification of Brazilian isolates. Pesq Vet Bras., v.32, n.7, p.619-622, 2012. doi: 10.1590/S0100-736X2012000700005.

BEZERRA JÚNIOR, P.S. et al. Equine intestinal pythiosis in Southern Brazil. Arq Bras Med Vet Zootec., v.62, n.2, p. 481-483, 2010. doi: 10.1590 / S0102-09352010000200031.

CALVANO, T.P. et al. Pythium aphanidermatum Infection following Combat Trauma. J. Clin. Microbiol., v.49, n.10, p. 3710-3713, 2011. doi: 10.1128 / JCM.01209-11.

DAVIS, D.J. et al. Relationship between temperature optima and secreted protease activities of three Pythium species and pathogenicity toward plant and animal hosts. Mycol. Res., v.110, n.1, p.96-103, 2006. doi: 10.1016/j.mycres.2005.08.009.

DE COCK, A.W. et al. Pythium insidiosum sp. Nov., the etiologic agent of pythiosis. J. Clin. Microbiol., v.25, n. 2, p.344-349, 1987.

DE HAAN, J. et al. Bosartige Schimmelkrankheit des Pferdes (Hyphomycosis destruens equi). Zentralbl Bakt Parasitenkd Infektionskr Hyg., v.31, p.758-763, 1902.

DE HAAN, J.; HOOGKAMER, L.J. Hypho-mycosis destruens. Veeartsennijkundige Bld. voor Ned., v.13, p.350-374, 1901.

DÓRIA, R.G.S. et al. Utilização da técnica de imuno-histoquímica para confirmar casos de pitiose cutânea equina diagnosticados por meio de caracterização clínica e avaliação histopatológica. Arq. Bras. Med. Vet. Zootec., v.66, n.1, p.27-33, 2014.

DYKSTRA, M. J. et al. A description of cutaneous-subcutaneous pythiosis in fifteen dogs. Med. Mycol., v. 37, n.6, p. 427-433, 
1999.

FARMER, A.R. et al. Combat-related Pythium aphanidermatum invasive wound infection: case report and discussion of utility of molecular diagnostics. J. Clin. Microbiol., v.53, n.6, p.19681975, 2015. doi: 10.1128 / JCM.00410-15.

FISCHER, J. R. et al. Gastrointestinal pythiosis in Missouri dogs: eleven cases. J. Vet. Diagn. Invest., v.6, n.3, p.380-382, 1994.

FIRMINO, M.O. et al. Intestinal intussusception secondary to enteritis caused by Pythium Insidiosum in a bitch: case report Arq. Bras. Med. Vet. Zootec., v.69, n.3, p.623-626, 2017.

FOIL, C.S. et al. A report of subcutaneous pythiosis in five dogs and a review of the etiologic agent Pythium spp. J. Am. Anim. Hosp. Assoc., v.20, p.959-966, 1984

FRANK, P.M.; MAKAFFEY, M.B. O estômago. In: TRALL, D.E. Diagnóstico de radiologia veterinária. São Paulo: Elsevier, 2014.

FROES, T.R. et al. Diagnóstico clínico e ultrassonográfico da Pitiose canina: relato de caso. Clín. Vet.., v.14, n.80, p.28-32, 2009.

FUJIMORI, M. et al. Pythium insidiosum colitis in a dog: treatment and clinical outcome. Cienc. Rural., v.46, n.3, p 526529, 2016. doi: 10.1590/0103-8478cr20150081.

GAASTRA, W. et al. Pythium insidiosum: an overview. Vet. Microbiol., v.146, p.1-16, 2010. doi: 10.1016/j. vetmic.2010.07.019.

GALIZA, G.J. et al. Ocorrência de micoses e pitiose em animais domésticos: 230 casos. Pesq. Vet. Bras., v.34, n.3, p.224-232, 2014.

GRAHAM, J. P. et al. Ultrasonographic features of canine gastrointestinal pythiosis. Vet. Radiol. Ultrasound., v.41, p.273$277,2000$.

GROOTERS, A.M.; GEE, M.K. Development of a nested polymerase chain reaction assay for the detection and identification of Pythium insidiosum. J. Vet. Intern. Med., v.16, p.147-152, 2002. doi: 10.1111/j.1939-1676. 2002.tb02346.x.

GROOTERS, A.M. et al. Development and evaluation of an enzyme-linked immunosorbent assay for the serodiagnosis of pythiosis in dogs. J. Vet. Intern. Med., v.16, n.2, p.142-146, 2002. doi: 10.1111/j.1939-1676. 2002.tb02345.x.

GROOTERS, A.M. Pythiosis, lagenidiosis, and zygomycosis in small animals. Vet. Clin. North Am. Small Anim. Pract., v.33, n.4, p.695-720, 2003. doi: 10.1016/S0195-5616(03)00034-2.

GROOTERS, A.M.; FOIL, C.S.O. Miscellaneous Fungal Infections. IN: GREENE, C.E. Infectious Diseases of the dog and cat. St. Louis: Elsevier, 2006.

HELMAN, R.G.; OLIVER, J. Pythiosis of the digestive tract in dogs from Oklahoma. J. Am. Anim. Hosp. Assoc., v.35, n.2, p.111114, 1999.

HNILICA, K. A. Dermatologia de pequenos animais - altas colorido e guia terapêutico. Rio de Janeiro: Elsevier, 2012.

HUNNING, P. S. et al. Obstrução intestinal por Pythium insidiosum em um cão: relato de caso. Arq. Bras. Med. Vet. Zootec., v.62, n.4, p.801-805, 2010. doi: 10.1590/S010209352010000400006.

HUSSEIN, M.R. Mucocutaneous Splendore-Hoeppli phenomenon. J. Cutan. Pathol., v.35, p.979-988, 2008. doi: 10.1111/j.1600-0560.2008. 01045.x.

JAEGER, G.H.; ROTSTEIN, D.S.; LAW, J.M. Pitiose prostática em um cão. J. Vet. Intern. Med., v.16, n.5, p.598-602, 2002. doi: 10.1111/j.1939-1676. 2002.tb02394.x.

KAMMARNJESADAKUL, P. et al. Phylogenetic analysis of Pythium insidiosum Thai strains using cytochrome oxidase II (COX II) DNA coding sequences and internal transcribed spacer regions (ITS). Med. Mycol., v.49, p.289-295, 2011. doi: 10.3109/13693786.2010.511282.

KLASSEN, G.R.; BALCERZAK, M.; DE COCK, A.W.A.M. 5S ribosomal RNA gene spacer as species-specific probes for eight species of Pythium. Phytopathol.., v.86, p.581-587, 1996.

KRAJAEJUN, T. et al. Effect of temperature on growth of the pathogenic oomycete Pythium insidiosum. Southeast Asian J. Trop. Med. Public Health, v.41, n.6, p.1462-1466, 2010.

LEAL, A. B. M.; FLORES, E.F.; SANTURIO, J.M. Pitiose. Cienc. Rural., v.31, n.4, p.735-743. 2001.

MACKEY, P.E. ET AL. CONIDIOBOLUS INCONGRUUS DISSEMINADO EM UM CÃO: RELATO DE CASO E REVISÃO DE LITERATURA. MED. MYCOL. CASE REP., V.8, P.24-28, 2015.

MARQUES, S.A.etal.Pythium insidiosum: relato do primeiro caso de infecção humana no Brasil. Na. Bras. Dermatol., v.81 n.5, 2006. doi: 10.1590/S0365-05962006000500012.

MARTINS, T.B. et al. Comparative Study of the Histopathology and Immunohistochemistry of Pythiosis in Horses, Dogs and Cattle. J. Comp. Path., v. 146, p.122-131, 2012. doi: 10.1016/j. jсра.2011.06.006.

MENDONÇA, L.F. et al. Pitiose mamária secundária à lesão cutânea em potra Quarto de Milha: relato de caso. Rev. Acad. Cienc Anim. v.15, n.1, p.341-342, 2017. doi: 0.7213/academica.15. S01.2017.170.

MENDOZA, L.; AJELLO, L.; McGINNIS, M.R. Infections caused by the oomycetous pathogen Pythium insidiosum. J. Mycol. Méd., v.6, n.4, p.151-164, 1996.

MENDOZA, L. et al. Serodiagnosis of Human and Animal Pythiosis Using an Enzyme-Linked Immunosorbent Assay. Clin. Diagn. Lab Immun. v.4, n.6, p.715-718, 1997.

MENDOZA, L; MANDY W; GLASS R. An improved Pythium insidiosum-vaccine formulation with enhanced immunotherapeutic properties in horses and dogs with pythiosis. Vaccine., v.21, p.2797-2804, 2003. doi: 10.1016/S0264$410 \mathrm{X}(03) 00225-1$.

MENDOZA, L. Pythium insidiosum. Topley and Wilson's Microbiology and Microbial Infections. 2016. Disponível: https://www.researchgate.net/publication/292754851 Pythium insidiosum. Acesso: 22 jan. 2019.

MENDOZA, L; KAUFMAN, L; STANDARD, P. Antigenic relationship between the animal and human pathogen Pythium Insidiosum and nonpathogenic Pythium species. J. Clin. Microbiol., v. 25, n. 11, p. 2159-2162,1987.

MENDOZA, L.; NEWTON, J.C.Immunology and immunotherapy of the infections caused by Pythium insidiosum. Med. Mycol., v.43, p.477-486, 2005. doi: 10.1080/13693780500279882.

MILLER, R. I. Treatment of equine phycomycosis by immunotherapy and surgery. Aust $J$ Vet., v.57, n.8, p.377-382, 1981. doi: 10.1111/j.1751-0813. 1981.tb00526.x.

MILLER, R.I., CAMPBELL, R.S.F. Clinical observations on equine phycomycosis. Aust $J$ Vet., v.58, p.221-226, 1982. doi: 10.1111/j.1751-0813. 1982.tb00681.x.

MILLER, R.I.Investigations into the biology of threephycomycotic agents pathogenic for horses in Australia. Mycopath., v.81, p.2328, 1983. 
MILLER, R.I. Phycomycosis gastrintestinal em 63 cães. Geléia. Veterinário. J. Am. Vet. Med. Assoc., v.186, n.5, p.473-478, 1985.

MÖLLER, E.M. et al. A simple and efficient protocol for isolation of high molecular weight DNA from filamentous fungi, fruit bodies, and infected plant tissues. Nucleic Acids Res., v.20, p.6115-6116,1992. doi: 10.1093/nar/20.22.6115.

OKADA, K. et al. Gastrointestinal basidiobolomycosis in a dog. J. Vet. Med. Sci., v.77, n.10, p.1311-1313, 2015.

PENNINCK, D.G. et al. The technique of percutaneous ultrasound guided biopsy in small animal gastrointestinal diseases. Vet. Radiol. Ultrasound., v.34, p.433-433, 1993. doi: 10.1111/j.17408261. 1993.tb02032.x.

PEREIRA, D.I.B. et al. Caspofungin in vitro and in vivo activity against Brazilian Pythium insidiosum strains isolated from animals. J. Antimicrob. Chemother., v.60, p.1168-1171, 2007. doi: $10.1093 / \mathrm{jac} / \mathrm{dkm} 332$.

PEREIRA, D.I.B. et al. Cutaneous and gastrointestinal pythiosis in a dog in Brazil. Vet. Res. Commun., v.34, p.301-306, 2010. doi: 10.1007/s11259-010-9354-9.

PESSOA, C.R.M. et al. Pythiosis of the digestive tract in sheep. J. Vet. Diagn. Invest., v.24, n.6, p.1133-1136, 2012.

PINTO, A.C.B.C.F. Princípios da tomografia computadorizada e da ressonância magnética. IN: TRALL, D.E. Diagnóstico de radiologia veterinária. São Paulo: Elsevier, 2014.

RAKEMAN, J.L. et al. Multilocus DNA Sequence Comparisons Rapidly Identify Pathogenic Molds. J. Clin. Microbiol., v.43, n.7, p.3324-3333, 2005. doi: 10.1128/JCM.43.7.3324-3333.2005.

RAKICH, P.M.; GROOTERS A.M.; TANG K. Gastrointestinal pythiosis in two cats. J. Vet, Diagn. Invest., v.17, n.3, p.262-269, 2005.

RASKIN, R.E. Categorias gerais de interpretação citológica. In: RASKIN, R.E; MYER, D.J. Citologia clínica de cães e gatos. Rio de Janeiro: Elsevier, 2011.

REAGAN, K.L. et al. Successful management of 3 dogs with colonic pythiosis using itraconzaole, terbinafine, and prednisone. J. Vet. Intern. Med., v.3, n.3, p.1434-1439, 2019. doi: 10.1111/ jvim. 15506

RECH, R.R.; GRAÇA D.L.; BARROS C.L. S. Pitiose em um cão: relato de caso e diagnósticos diferenciais. Clínica Vet., v.9, n.50, p.68-72, 2004.

RIEDESEL, E.A. O intestino delgado. In: TRALL, D.E. Diagnóstico de radiologia veterinária. São Paulo: Elsevier, 2014.

RIET-CORREA, F.; FERREIRA, J.L.M.; SCHILD, A.L. Boletim do Laboratório Regional de Diagnóstico - UFPEL. Pelotas: UFPEL, 1998.
RODRIGUES, A. et al. Intestinal dog pythiosis in Brazil. J. Mycol. Med., v.16, n.1, p.37-41, 2006. doi: 10.1016/j. mycmed.2005.10.006.

SANTOS, C.E.P. et al. Epidemiological survey of equine pythiosis in the Brazilian Pantanal and nearby areas: Results of 76 cases. J. Equine Vet. Sci., v.34, p.270-274, 2014. doi: 10.1016/j. jevs.2013.06.003.

SANTÚRIO, J.M.; FERREIRO, L. Pitiose: uma abordagem micológica e terapêutica. Porto Alegre: UFRGS, 2008.

SANTURIO, J.M.; LEAL, A.; MONTEIRO, A.B. Pythiose. In: LEFÈVRE P.C.; BLANCOU J., CHERMETTE R. Principales Maladies Infectieuses et Parasitaires du Bétail - Europe et Régions Chaudes. Paris: TEC \& DOC, 2003.

SANTURIO, J.M. et al. Three types of immunotherapics against pythiosis insidiosum developed and evaluated. Vaccine., v.21, p.2535-2540, 2003. doi: 10.1016/S0264-410X(03)00035-5.

SANTURIO, J.M. et al. Pitiose: uma micose emergente. Acta Scie Vet., v.34, p.1-14, 2006.

SANTURIO J.M. et al. Teste de ELISA indireto para o diagnóstico sorológico de pitiose. Pesq Vet Bras., v.26, n.1, p.47-50, 2006.

SCHURKO, A. et al. Evidência de clusters geográficos. Diferenças genéticas moleculares entre cepas de Pythium insidiosum da Ásia, Austrália e Américas são exploradas. Mycol., v.95, p.200208, 2003

SUPABANDHU, J. et al. Isolation and identification of the human pathogen Pythium insidiosum from environmental samples collected in Thai agricultural areas. Med Mycol., v.46, p.41-52, 2008. doi: 10.1080/13693780701513840.

TORRES, L.M. et al. Canine Cutaneous Pythiosis: case report. Ars Vet., v.30, n.2, p.77-82, 2014.

TROST, M. E. et al. Aspectos clínicos, morfológicos e imunoistoquímicos da Pitiose gastrintestinal canina. Pesq Vet Bras., v.29, n.8, p.673-679, 2009.

UBIALI, D.G. et al. Pathology of Nasal Infection caused by Conidiobolus lamprauges and Pythium insidiosum in Sheep. J Comp Pathol., v.149, p.137-145, 2013. doi: 10.1016/j. jсра.2012.12.002.

VANITTANAKOM, N. et al. Detecção molecular de Pythium insidiosum do solo em áreas agrícolas tailandesas. Int. J. Med. Microbiol., v.304, n.3, p.321-326, 2014.

VILELA, R. et al. Pythium insidiosum isolado de larvas de mosquitos infectados no Brasil central. Acta Trop., v.185, p.344348, 2018. doi: 10.1016/j.actatropica.2018.06.014.

WALKER, C.A.; VAN WEST, P. Zoospore development in the oomycetes. Fungal Biol Rev., v.21, p.10-18, 2007. doi: doi. org/10.1016/j.fbr.2007.02.001. 